\title{
Mixed Micelles Composed of Peptides and Gadolinium Complexes as Tumor-Specific Contrast Agents in MRI: A SANS Study
}

\author{
Gaetano Mangiapia, ${ }^{\dagger}$ Antonella Accardo, ${ }^{\S}$ Fabrizio Lo Celso, ${ }^{\ddagger}$ Diego Tesauro,${ }^{\S}$ \\ Giancarlo Morelli, $§$ Aurel Radulescu," and Luigi Paduano*, $\dagger$ \\ Dipartimento di Chimica, Università degli Studi di Napoli “Federico II”, Via Cinthia, 80126 Napoli, Italy, \\ Dipartimento di Chimica Biologica, Centro Interuniversitario per la Ricerca sui Peptidi Bioattivi (CIRPeB), \\ Università degli Studi di Napoli "Federico II", Via Mezzocannone 6, 80134 Napoli, Italy, Dipartimento di \\ Chimica Fisica, Università degli Studi di Palermo, Viale delle Scienze, Parco d'Orleans II, \\ 90128 Palermo, Italy, and Institute for Solid State Research, Research Center Jülich GmbH, \\ Jülich D52425, Germany
}

Received: April 7, 2004; In Final Form: July 21, 2004

\begin{abstract}
A detailed structural investigation on mixed micelle aggregates as target-specific contrast agents for magnetic resonance imaging technique has been carried out by way of small angle neutron scattering measurements. These mixed micelles are formed by two new amphiphilic molecules formed by a bioactive peptide and a claw moiety. The first molecule, $\mathrm{C}_{18} \mathrm{H}_{37} \mathrm{CONH}(\mathrm{AdOO})_{x}-\mathrm{G}-\mathrm{CCK} 8(\mathrm{C} 18 \mathrm{~L} x \mathrm{CCK} 8, x=2,5)$, contains an 18carbon-atom alkylic chain bound to the C-terminal of the cholecystokinin octapeptide amide (CCK 26-33 or CCK8) and is able to bind to the overexpressed CCK receptor of some tumor cells. The second molecule,

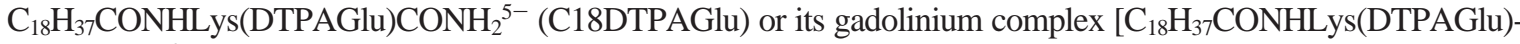
$\left.\mathrm{CONH}_{2} \mathrm{Gd}\right]^{2-}$, C18DTPAGlu(Gd), contains the same 18-carbon-atom alkylic chain bound, through a lysine residue, to the DTPAGlu chelating agent. Small angle neutron scattering measurements have been performed on ternary systems at different total concentrations and at various ratios of the two molecules. The effect of the concentration on the aggregation number as well as on the shape of the micelle has been investigated. Furthermore in order to optimize the exposure of the peptide on the micelle surface, C18L $x$ CCK8 having the spacer L of different length has been used. The pure binary systems of the synthesized molecules are also presented.
\end{abstract}

\section{Introduction}

Magnetic resonance imaging (MRI) is a very promising noninvasive medical diagnostic procedure giving high-quality images of the inside of the human body. MRI is based on the same principles of nuclear magnetic resonance (NMR) and measures the characteristics of hydrogen nuclei of water modified by chemical environment. To enhance the quality of the images, a reporter compound (contrast agent) has to be accumulated in the area of interest. ${ }^{1,2}$ The contrast activity is generally obtained by a paramagnetic atom that increases the relaxivity of the surrounding water molecules, i.e., produces an alteration of the water protons' relaxation time that it easily detected through the MRI technique. This effect is enhanced if the paramagnetic atom is complexed in a large size molecule that has a slow rotation. Due to the very low sensitivity, MRI needs a relatively high concentration $\left(\sim 10^{-4} \mathrm{~mol} / \mathrm{L}\right)$ of contrast agents such as paramagnetic $\mathrm{Gd}(\mathrm{III})$ complexes. To reach the required local concentration of the contrast agent, many nonspecific supramolecular systems have been developed such as liposomes ${ }^{3}$ and other microparticulates, ${ }^{4}$ micelles, ${ }^{5}$ dendri-

* Corresponding author. Tel: +39 081 674229. Fax: +39081674090. E-mail: luigi.paduano@unina.it. II".

'Dipartimento di Chimica, Università degli Studi di Napoli "Federico

$\S$ Dipartimento di Chimica Biologica, Università degli Studi di Napoli "Federico II".

† Università degli Studi di Palermo.

"Institute for Solid State Research.

10.1021/jp048466h CCC: $\$ 27.50$ @ 2004 American Chemical Society Published on Web 10/14/2004 mers,${ }^{6}$ linear polymers,${ }^{7,8}$ proteins,${ }^{9}$ or peptides, ${ }^{10}$ all of these derivatized with the metal complex of interest. Among these carriers, due to their easily controlled properties and good pharmacological characteristics, micelle aggregates are very promising contrast agents. ${ }^{11,12}$

Currently the research in this field is devoted to develop new contrast agents with improved properties such as high contrast activity (high relaxivity) and high specificity toward target cells or organs. In fact, high relaxivity allows reducing the concentration of the reporter compound in the area of interest, while the target specificity allows addressing the reporter compound only in a restricted area, such as membrane receptors overexpressed by cancer cells. Therefore, in both cases, the total amount of the contrast agent to be injected for diagnostic analysis could be reduced.

With these aims we have recently synthesized new amphiphilic molecules containing a chelating agent, DTPAGlu, able to complex the $\mathrm{Gd}(\mathrm{III})$ ion or a bioactive peptide that shows high affinity for the cholecystokinin receptors that are overexpressed by the cells in many tumors ${ }^{13-15}$ (see Figure 1 for the structure of the molecules). These molecules have been assembled in supramolecular micellar aggregates that fulfill the above properties. In fact the supramolecular aggregation of the C18DTPAGlu(Gd) complexes in the mixed micelle gives rise to a slow rotation and, consequently, increases the proton relaxivity with respect to that shown by monomeric Gd(III)chelate complexes, ${ }^{12}$ while the bioactive peptide on the external 


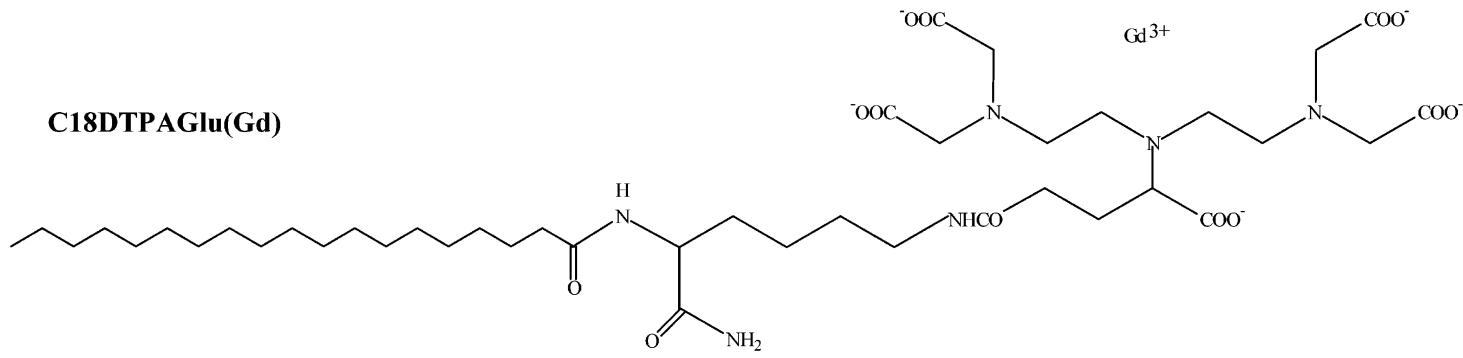

C18LxCCK8
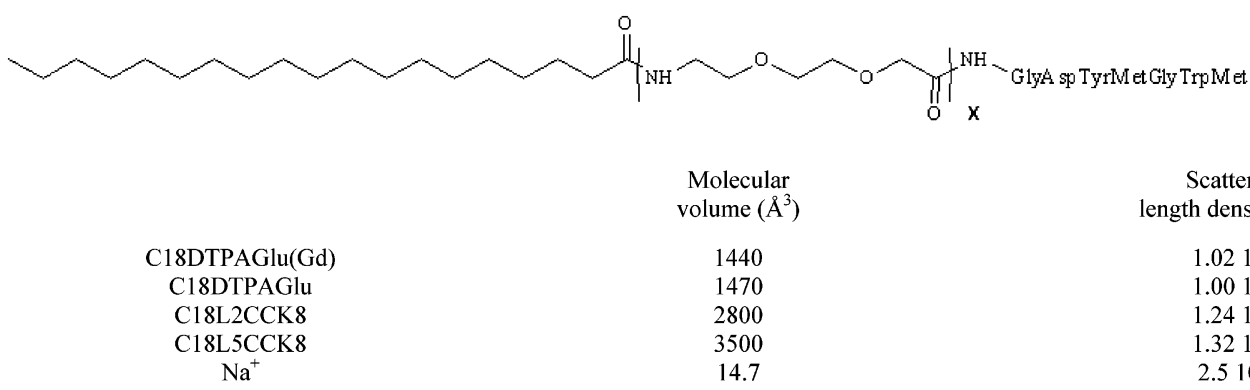

\begin{tabular}{|c|}
\hline $\begin{array}{l}\text { Molecular } \\
\text { volume }\left(\AA^{3}\right)\end{array}$ \\
\hline 1440 \\
\hline 1470 \\
\hline 2800 \\
\hline 3500 \\
\hline 14.7 \\
\hline
\end{tabular}

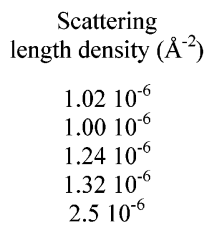

Figure 1. Chemical structure and relevant SANS parameters of the monomers forming micelles.

surface of the micelle should address the Gd-containing aggregates on the target cells.

In this paper we present a complete small angle neutron scattering characterization of mixed micelles formed in aqueous solution by the two monomers C18L $x$ CCK8 and C18DTPAGlu in the presence and in the absence of $\mathrm{Gd}(\mathrm{III})$ ion along with their corresponding pure aggregates.

Some of the systems presented here have been reported in a recent paper of some of the authors. ${ }^{16}$ However, the structural information obtained through the previous measurements has raised some concerns on the specificity of the mixed aggregate that in turn depends on the complete exposure beyond the micelle surface of the bioactive part of C18L2CCK8. In particular, it was found that the length of the spacer was nearly equal to the thickness of the hydrophilic shell, so that part of the bioactive molecule could be hidden in the DTPAGlu moiety. Thus a larger number of oxoethylene spacers, AdOO, has been inserted between the lipophilic tail and the CCK8 peptide in the monomer containing the peptide.

The second purpose of the present paper was to draw attention to the possible micellar growth. This is generally observed as the solute concentration is raised. A large size micelle should improve the efficiency of the designed aggregates because a large number of $\mathrm{Gd}$ atoms can be addressed on a relevant biological target. Finally the effect of the bioactive molecule's presence in the micelle has been analyzed by studying samples containing aggregates formed by different ratios of C18L2CCK8 (or C18L5CCK8) and C18DTPAGlu.

All the collected results are discussed and compared with those previously obtained.

\section{Experimental Section}

Materials. Protected $\mathrm{N}^{\alpha}$-Fmoc-amino acid derivatives, coupling reagents, and Rink amide MBHA resin were purchased from Calbiochem-Novabiochem (Laufelfingen, Switzerland). The Fmoc-8-amino-3,6-dioxaoctanoic acid (Fmoc-AdOO-OH) was purchased from Neosystem (Strasbourg, France). The DTPAGlu pentaester, $N, N$-bis[2-[bis[2-(1,1-dimethyletoxy)-2oxoethyl]amino]ethyl]-L-glutamic acid 1-(1,1-dimethylethyl)ester, was provided by Bracco Imaging SpA (Milan, Italy) and was used without further purification. For its synthesis refer to published methods. ${ }^{17}$ All other chemicals were commercially available by Sigma-Aldrich (St. Louis, MO), Fluka (Bucks, Switzerland), or LabScan (Dublin, Ireland) and were used as received unless otherwise stated.

Chemical Synthesis. $\mathrm{C}_{18} \mathrm{H}_{37} \mathrm{CONH}(\mathrm{AdOO})_{2}-\mathrm{G}-\mathrm{CCK} 8$

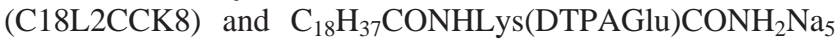
were synthesized as previously described. ${ }^{16}$

$\mathrm{C}_{18} \mathrm{H}_{37} \mathrm{CONH}(\mathrm{AdOO}){ }_{5}$-G-CCK8 (C18L5CCK8) was synthesized according to the synthetic procedure used for C18L2CCK8. The five residues of Fmoc-AdOO-OH were coupled by using a single coupling procedure and an excess of 2 equiv. Yield for aliphatic acid coupling, monitored by the Kaiser test, was in the range $95-98 \%$. At the end of the solid-phase synthesis, the fully protected resin was treated with TFA containing triisopropylsilane $(2.0 \%)$, ethanedithiole $(2.5 \%)$, and water $(2.5 \%)$ for deprotection and cleavage, and the free product precipitated at $0{ }^{\circ} \mathrm{C}$ by adding ethyl ether dropwise. ${ }^{18}$ Purification of the crude mixture was carried out by RP-HPLC, Waters (Milford, MA) model Delta Prep 4000 equipped with a UV lambda-Max Model 481 detector using a Vydac C4 column (Columbia, MD), $22 \times 250 \mathrm{~mm}$, eluted with an $\mathrm{H}_{2} \mathrm{O} / 0.1 \%$ TFA (A) and $\mathrm{CH}_{3}-$ CN/0.1\% TFA (B) linear gradients at $20 \mathrm{~mL} / \mathrm{min}$ flow rate, $t_{\mathrm{R}}$ $=19.2$ min, purity $>95 \%$. Mass spectroscopy, carried out on a Maldi-tof Voyager-DE Perseptive Biosystem (Framingham, MA) apparatus using $\alpha$-cyano-4-hydroxycynnamic acid as matrix and bovine insulin as internal reference, confirms the product identity: $\mathrm{C}_{18} \mathrm{H}_{37} \mathrm{CONH}(\mathrm{AdOO})_{5}-\mathrm{G}-\mathrm{CCK} 8, \mathrm{MW}=2119$ (calcd 2119).

The preparation of the gadolinium complex, C18DTPAGlu$(\mathrm{Gd})$, has been carried out by adding stoichiometric amounts of $\mathrm{GdCl}_{3}$ to the aqueous solution of the C18DTPAGlu ligand at the neutral $\mathrm{pH}$ at room temperature, as previously described. ${ }^{16}$

Preparation of Solutions. All solutions were prepared by weighting using heavy water, $\mathrm{D}_{2} \mathrm{O}$ (Sigma-Aldrich, purity $>$ $99.8 \%$ ), keeping the system at $\mathrm{pH}=7.4$ by using a buffer solution composed of $0.10 \mathrm{~mol} / \mathrm{L} \mathrm{H}_{2} \mathrm{PO}_{4}{ }^{-} / \mathrm{HPO}_{4}{ }^{2-}(1: 1)$ and $34 \mathrm{mmol} / \mathrm{L} \mathrm{NaCl}$ in $\mathrm{D}_{2} \mathrm{O}$. $\mathrm{pH}$ measurements were made by using a MeterLab PHM 220 pH meter. The instrument was calibrated with standard buffers at $\mathrm{pH}=7$ and $\mathrm{pH}=10$. In most cases the samples to be measured were prepared from stock solutions, and all solutions were stirred at room temperature until complete dissolution and then used without further treatment. 

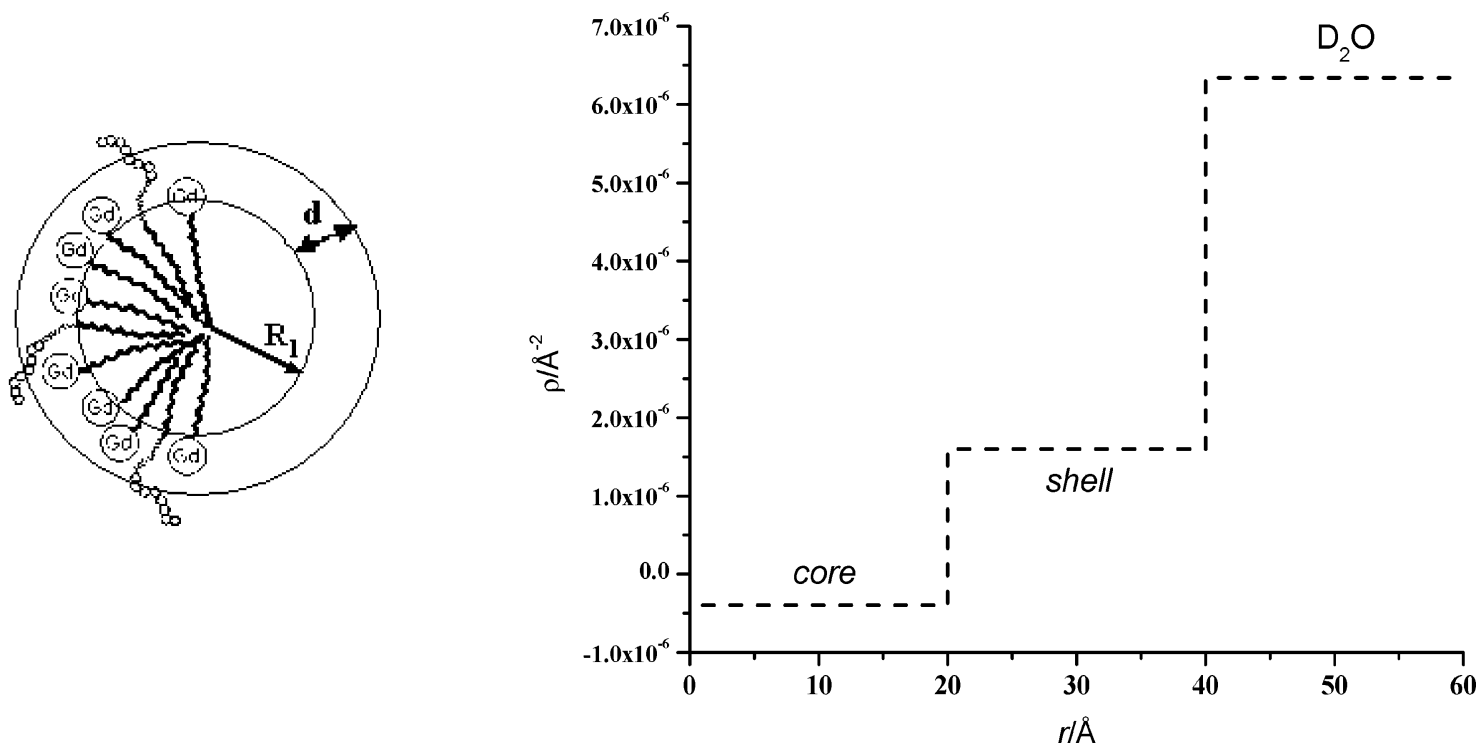

Figure 2. Approximate scheme of mixed micelle C18DTPAGlu(Gd)-C18L5CCK8 and scattering length density profile of the aggregate.

Measurements on samples of C18DTPAGlu- $\mathrm{D}_{2} \mathrm{O}$ at 0.00301 , $0.0105,0.0120$, and $0.0192 \mathrm{~mol} \mathrm{~kg}^{-1}$ and on C18DTPAGlu$(\mathrm{Gd})-\mathrm{D}_{2} \mathrm{O}$ at 0.00301 and $0.00794 \mathrm{~mol} \mathrm{~kg}^{-1}$ were carried out. Two binary solutions of C18L2CCK8- $\mathrm{D}_{2} \mathrm{O}$ and C18L5CCK8$\mathrm{D}_{2} \mathrm{O}$ at their solubility limit $\left(\sim 10^{-4} \mathrm{~mol} \mathrm{~kg} \mathrm{~kg}^{-1}\right)$ were also prepared in order to detect the presence of possible pure micelle aggregates.

Ternary solutions of C18DTPAGlu-C18L2CCK8- $\mathrm{D}_{2} \mathrm{O}$, C18DTPAGlu(Gd)-C18L2CCK8- $\mathrm{D}_{2} \mathrm{O}, \quad$ C18DTPAGluC18L5CCK8- $\mathrm{D}_{2} \mathrm{O}$, and C18DTPAGlu(Gd)-C18L5CCK8$\mathrm{D}_{2} \mathrm{O}$ at increasing concentration of the solutes were also studied. In these samples the imposing concentration ratio between the solutes was such as to have an average of peptide derivatives per micelle ranging from two to six.

Small Angle Neutron Scattering Measurements. Small angle neutron scattering measurements were performed at the KWS2 facility located at the Forschungszentrum of Jülich, Germany. Neutrons with an average wavelength $\lambda$ of $7 \AA$ and a wavelength spread $\Delta \lambda / \lambda \leq 0.1$ were used. A two-dimensional array detector at two different sample-to-detector distances, 2 and $8 \mathrm{~m}$, detected neutrons scattered from the samples. These configurations allowed collecting the scattering cross section in a range of moment transferred $q$ between 0.01 and $0.12 \AA^{-1}$. Samples were contained in $1 \mathrm{~mm}$ path length HELLMA 404QX quartz cells, and measurement times ranged between 20 min and $2 \mathrm{~h}$.

Raw data were corrected for electronic background and empty cell scattering. Detector efficiency corrections and transformation to absolute scattering cross sections $(\mathrm{d} \sigma / \mathrm{d} \Omega)(q)$ were made with a secondary Lupolene standard according to the standard procedure. ${ }^{19,20}$

Modeling of Micelles. The scattering cross section ( $\mathrm{d} \sigma / \mathrm{d} \Omega)$ $(q)$ of a collection of monodisperse bodies is described by the following equation: ${ }^{21}$

$$
\frac{\mathrm{d} \sigma}{\mathrm{d} \Omega}(q)=n_{\mathrm{b}} P(q) S(q)+\left(\frac{\mathrm{d} \sigma}{\mathrm{d} \Omega}\right)_{\mathrm{inc}}
$$

where $n_{\mathrm{b}}$ is the number density of scattering bodies, $P(q)$ and $S(q)$ are the form factor and the structure factor of the bodies, while $(\mathrm{d} \sigma / \mathrm{d} \Omega)_{\text {inc }}$ is the incoherent scattering cross section. The form factor $P(q)$ contains information on the shape of the scattering objects, while the structure factor $S(q)$ accounts for interparticle correlations and is normally important for concentrated or charged systems.
The micelle solutions are assumed to be composed of a small amount of monomeric surfactants with concentration equal to critical micelle concentration $c_{\mathrm{M}}$ (phase separation model) and uniform-sized spherical micelles (mixed or pure, depending on the system analyzed) with a mean aggregation number $N_{\text {agg }}$ and an actual charge $z$. According to the phase separation model adopted, the density of micelles is given by

$$
n_{\mathrm{b}}=\frac{c-c_{\mathrm{M}}}{N_{\mathrm{agg}}} L_{\mathrm{A}}
$$

where $c$ is the stoichiometric molar concentration and $L_{\mathrm{A}}$ the Avogadro constant.

The micelles have been assumed to have a hydrophobic core composed of the close-packed 18-carbon-atom alkylic chains and a hydrated hydrophilic shell formed by the rest of the molecules, some counterions $\left(\mathrm{Na}^{+}\right)$, and some solvent molecules $\left(\mathrm{D}_{2} \mathrm{O}\right)$. We assume the micelles formed by a spherical hydrophobic core with a radius $R_{1}$ and a hydrophilic shell with a constant thickness $d$. The scattering contribution from the free counterions and surfactants is orders of magnitude weaker than that from the micelles. Hence the scattering from all the species but the micelles is treated as a flat background added to the incoherent scattering cross section. A schematic composition of a micelle is represented in Figure 2 along with a schematic profile of scattering length densities.

According to the geometry adopted, the form factor can be written as ${ }^{22}$

$P(q)=\left[V_{1}\left(\rho_{1}-\rho_{2}\right) \frac{3 j_{1}\left(q \mathrm{R}_{1}\right)}{q R_{1}}+V_{2}\left(\rho_{2}-\rho_{0}\right) \frac{3 j_{1}\left(q R_{2}\right)}{q R_{2}}\right]^{2}$

where $R_{2}$ is the radius of the micelles, $R_{2}=R_{1}+d, V_{i}=4 \pi R_{i}{ }^{3}$ / $3, \rho_{1}$ and $\rho_{2}$ are the scattering length densities of the hydrophobic core and the hydrophilic shell, respectively, $\rho_{0}$ represents the scattering length density of the solvent, and $j_{i}(x)$ is the firstorder Bessel function:

$$
j_{i}(x)=\frac{\sin (x)-x \cos (x)}{x^{2}}
$$

The structure factor was computed by means of the rescaled mean spherical approximation (RMSA) using a screened Coulombic potential. 22,23 
The volume of a chain $v_{\mathrm{c}}$ constituted by $m$ carbon atoms is given by the Tanford equation: ${ }^{24}$

$$
\frac{v_{\mathrm{c}}}{\AA^{3}}=54.3+24.8(m-1)
$$

In the present case $m=18$, and from $v_{\mathrm{c}}$ and $N_{\mathrm{agg}}$ the hydrophobic core radius $R_{1}$ is readily calculated, assuming a close-packed distribution:

$$
N_{\mathrm{agg}} v_{\mathrm{c}}=\frac{4}{3} \pi R_{1}^{3}=V_{1}
$$

The "dry" volumes as well as the scattering densities used in the present work for C18DTPAGlu(Gd), C18DTPAGlu, C18L2CCK8, C18L5CCK8, $\mathrm{D}_{2} \mathrm{O}$ molecules, and the $\mathrm{Na}^{+}$ion are reported in Figure 1.

Regarding the volume of the hydrophilic shell we obtain

$$
\begin{array}{r}
V_{2}-V_{1}=N_{\mathrm{agg}}\left[f v_{\mathrm{C} 18 \mathrm{DTPAGlu}(\mathrm{Gd})}+(1-f) v_{\mathrm{C} 18 \mathrm{CCK} 8}+\right. \\
\left.n_{\mathrm{w}} v_{\mathrm{D}_{2} \mathrm{O}}\right]+n_{\mathrm{Na}^{+}} v_{\mathrm{Na}^{+}}-N_{\mathrm{agg}} v_{\mathrm{c}}
\end{array}
$$

where $f$ is the fraction of C18DTPAGlu(Gd) in the mixed micelle, $n_{\mathrm{w}}$ is the number of solvent molecules per surfactant, and $n_{\mathrm{Na}^{+}}$is the number of counterions $\mathrm{Na}^{+}$condensed on a micelle.

From the composition and the volume of the hydrophobic core, it is possible to evaluate its scattering density:

$$
\rho_{1}=\frac{N_{\mathrm{agg}}\left[m b_{\mathrm{C}}+(2 m+1) b_{\mathrm{H}}\right]}{N_{\mathrm{agg}} v_{\mathrm{c}}}
$$

where $b_{\mathrm{C}}$ and $b_{\mathrm{H}}$ are the scattering lengths of the carbon and the hydrogen nuclei, respectively.

The scattering density of the hydrophilic shell of the mixed micelle constituted by C18DTPAGlu(Gd) and C18L $x$ CCK8 may be calculated analogously by

$$
\begin{aligned}
& \rho_{2}= \\
& f \sum_{\mathrm{DTPAGlu}(\mathrm{Gd})} b_{i}+(1-f) \sum_{\mathrm{LxCCK} 8} b_{i}+n_{\mathrm{w}}\left(2 b_{\mathrm{D}}+b_{\mathrm{O}}\right)+n_{\mathrm{Na}^{+}} b_{\mathrm{Na}^{+}} \\
& N_{\mathrm{agg}}\left[f v_{\mathrm{C} 18 \mathrm{DTPAGlu}(\mathrm{Gd})}+(1-f) v_{\mathrm{C} 18 \mathrm{LxCCK} 8}+n_{\mathrm{w}} v_{\mathrm{D}_{2} \mathrm{O}}\right]+ \\
& n_{\mathrm{Na}^{+}} v_{\mathrm{Na}^{+}}-N_{\mathrm{agg}} v_{\mathrm{c}}
\end{aligned}
$$

where $b_{\mathrm{D}}, b_{\mathrm{O}}$, and $b_{\mathrm{Na}^{+}}$are the scattering lengths of deuterium, oxygen, and sodium, respectively. In eq 9 the summations are extended over all the atoms of one molecule of C18DTPAGlu(Gd) and C18L $x$ CCK8 belonging to the hydrophilic shell. If we indicate with $Z$ the charge of a DTPAGlu $(\mathrm{Gd})$ ion (the only charged surfactant) through a charge balance, we obtain for $n_{\mathrm{Na}^{+}}{ }^{+}$

$$
n_{\mathrm{Na}^{+}}=\left|N_{\mathrm{agg}} f Z\right|-|z|
$$

Inserting eqs $2,3,6,8,9$, and 10 in eq 1 we obtain an expression depending on $c, c_{\mathrm{M}}, N_{\mathrm{agg}}, z, n_{\mathrm{w}}$, and $f$. It is worth noting that in the computation of structure factors the ionic strength that depends also on the presence of the buffer $\mathrm{H}_{2}$ $\mathrm{PO}_{4}{ }^{-} / \mathrm{HPO}_{4}{ }^{2-}$ and on $\mathrm{NaCl}$ has been taken into account. The equations developed are still valid for ternary systems where C18DTPAGlu replaces the complex C18DTPAGlu(Gd) and for binary systems C18DTPAGlu $(\mathrm{Gd})-\mathrm{D}_{2} \mathrm{O}$ and C18DTPAGlu$\mathrm{D}_{2} \mathrm{O}$. For the last two systems we obviously have $f=1$.

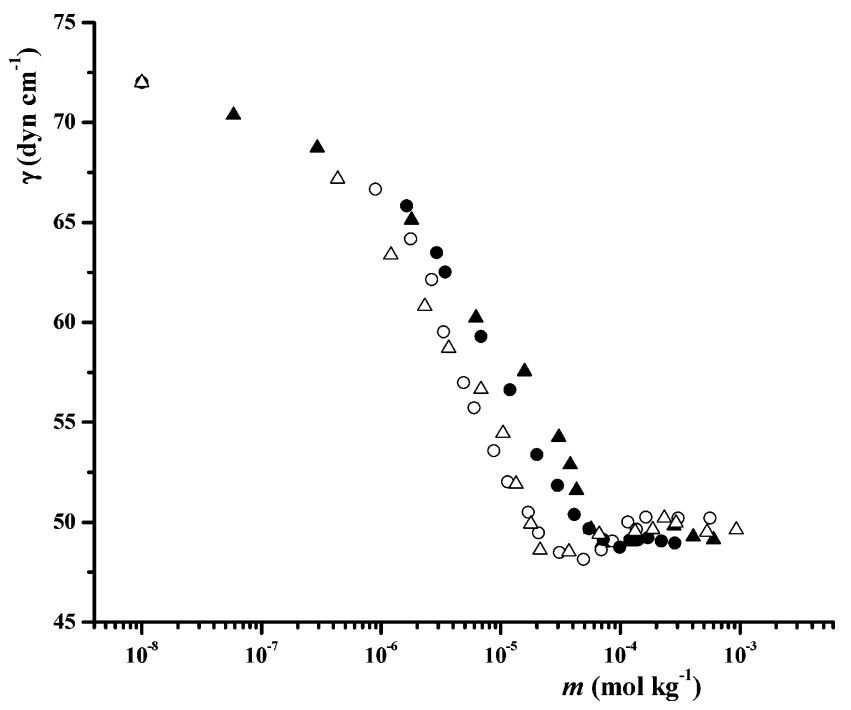

Figure 3. Surface tension measurements carried out on the following systems: ${ }^{16}(\triangle)$ C18DTPAGlu $-\mathrm{H}_{2} \mathrm{O},(\boldsymbol{\Delta}) \mathrm{C} 18 \mathrm{DTPAGlu}(\mathrm{Gd})-\mathrm{H}_{2} \mathrm{O},(\mathrm{O})$ C18DTPAGlu-C18L2CCK8- $\mathrm{H}_{2} \mathrm{O}(14: 1)$, (•) C18DTPAGlu(Gd)C18L2CCK8 $-\mathrm{H}_{2} \mathrm{O}(20: 1)$. For ternary systems total molality of the solutes is reported. These measurements have been reported and widely discussed elsewhere. ${ }^{16}$

By performing a nonlinear least-squares fitting we have been able to extract quantitative parameters from experimental data as described in the next section.

\section{Results and Discussion}

As already described, SANS experiments were performed on the C18DTPAGlu $-\mathrm{D}_{2} \mathrm{O}$ and the C18DTPAGlu $(\mathrm{Gd})-\mathrm{D}_{2} \mathrm{O}$ binary systems at several concentrations. Two binary solutions of C18L2CCK8- $\mathrm{D}_{2} \mathrm{O}$ and C18L5CCK8 $-\mathrm{D}_{2} \mathrm{O}$, at the solubility limit $\left(\sim 10^{-4} \mathrm{~mol} \mathrm{~kg}^{-1}\right)$, were also prepared in order to verify the absence of pure micelle aggregates. Finally, measurements on samples of C18DTPAGlu-C18L2CCK8$\mathrm{D}_{2} \mathrm{O}, \mathrm{C} 18 \mathrm{DTPAGlu}(\mathrm{Gd})-\mathrm{C} 18 \mathrm{~L} 2 \mathrm{CCK} 8-\mathrm{D}_{2} \mathrm{O}, \mathrm{C} 18 \mathrm{DTPAGlu}-$ C18L5CCK8 $-\mathrm{D}_{2} \mathrm{O}$, and C18DTPAGlu(Gd)-C18L5CCK8$\mathrm{D}_{2} \mathrm{O}$ ternary systems, prepared as to have an average of peptide derivatives per micelle extended from two to six, were carried out. All samples, except those containing only C18L2CCK8 or C18L5CCK8, have been prepared at concentrations well above the observed value of the cmc. The values of the critical micelle concentration were evaluated through surface tension $(\gamma)$ measurements and were reported and discussed elsewhere. ${ }^{16}$ In Figure 3 the curves of the surface tension concentration dependence corresponding to the systems presented in the present article have been reported.

Binary Systems: C18DTPAGlu- $-\mathrm{D}_{2} \mathrm{O}$, C18DTPAGlu(Gd) $-\mathrm{D}_{2} \mathrm{O}$, C18L2CCK8- $\mathrm{D}_{2} \mathrm{O}$, and C18L5CCK8 $-\mathrm{D}_{2} \mathrm{O}$. In Figure 4 the scattering cross sections obtained for binary systems C18L2CCK8- $\mathrm{D}_{2} \mathrm{O}, \mathrm{C} 18 \mathrm{~L} 5 \mathrm{CCK} 8-\mathrm{D}_{2} \mathrm{O}, \mathrm{C} 18 \mathrm{DTPAGlu}-\mathrm{D}_{2} \mathrm{O}$, and C18DTPAGlu(Gd) $-\mathrm{D}_{2} \mathrm{O}$ are presented. A substantially flat profile of the scattering intensity for samples containing the C18L2CCK8 $\left(\sim 10^{-4} \mathrm{~mol} \mathrm{~kg}{ }^{-1}\right)$ and C18L5CCK8 $\left(\sim 10^{-4} \mathrm{~mol}\right.$ $\mathrm{kg}^{-1}$ ) molecules can be observed, confirming the absence of aggregates. On the other hand, sensible values of the scattering cross section are observed for the systems containing C18DTPAGlu in the range of concentration from 0.00301 to $0.0192 \mathrm{~mol} \mathrm{~kg}^{-1}$. The curves show a rising peak, whose magnitude and position are a strong function of concentration; the shoulder moves to higher $q$ and at the highest concentration explored appears as a single broad maximum.

This behavior is characteristic of systems containing an increasing number of interacting aggregates. Replacement of 


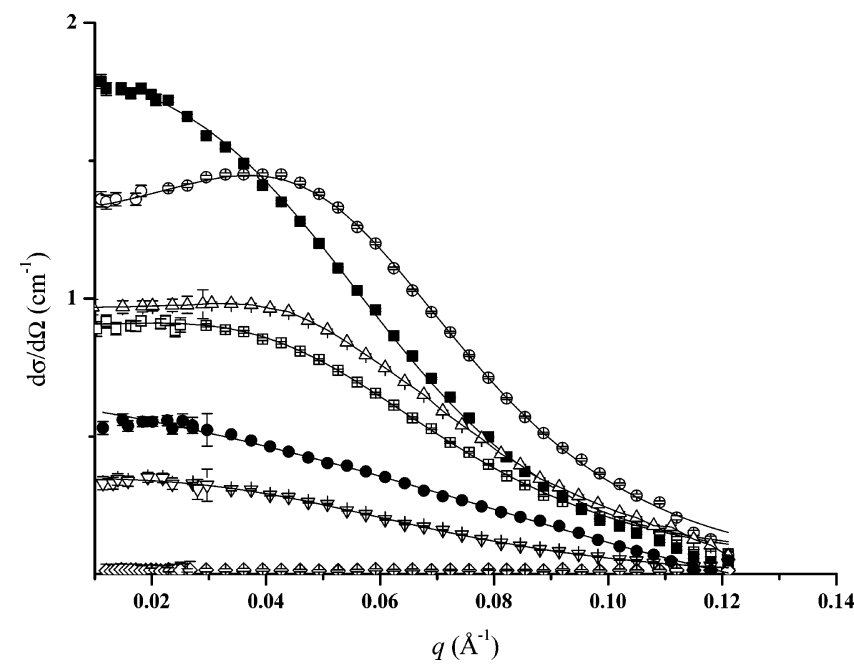

Figure 4. Scattering cross section measured on the following systems: $(\diamond)$ C18L2CCK8 $\left(\sim 10^{-4} \mathrm{~mol} \mathrm{~kg}^{-1}\right)-\mathrm{D}_{2} \mathrm{O},(\diamond)$ C18L5CCK8 $\left(\sim 10^{-4} \mathrm{~mol} \mathrm{~kg}^{-1}\right)-\mathrm{D}_{2} \mathrm{O},(\nabla)$ C18DTPAGlu $\left(0.00301 \mathrm{~mol} \mathrm{~kg}^{-1}\right)-\mathrm{D}_{2} \mathrm{O}$, (口) C18DTPAGlu $\left(0.0105 \mathrm{~mol} \mathrm{~kg}^{-1}\right)-\mathrm{D}_{2} \mathrm{O},(\triangle)$ C18DTPAGlu $(0.0120$ mol kg-1)- $\mathrm{D}_{2} \mathrm{O}$, (O) C18DTPAGlu (0.0192 mol kg-1)- $\mathrm{D}_{2} \mathrm{O}$, (৩) C18DTPAGlu(Gd) $\left(0.00301 \mathrm{~mol} \mathrm{~kg}^{-1}\right)-\mathrm{D}_{2} \mathrm{O}$, (ם) C18DTPAGlu(Gd) $\left(0.00794 \mathrm{~mol} \mathrm{~kg}{ }^{-1}\right)-\mathrm{D}_{2} \mathrm{O}$. Solid lines are the fitting curves; see text.

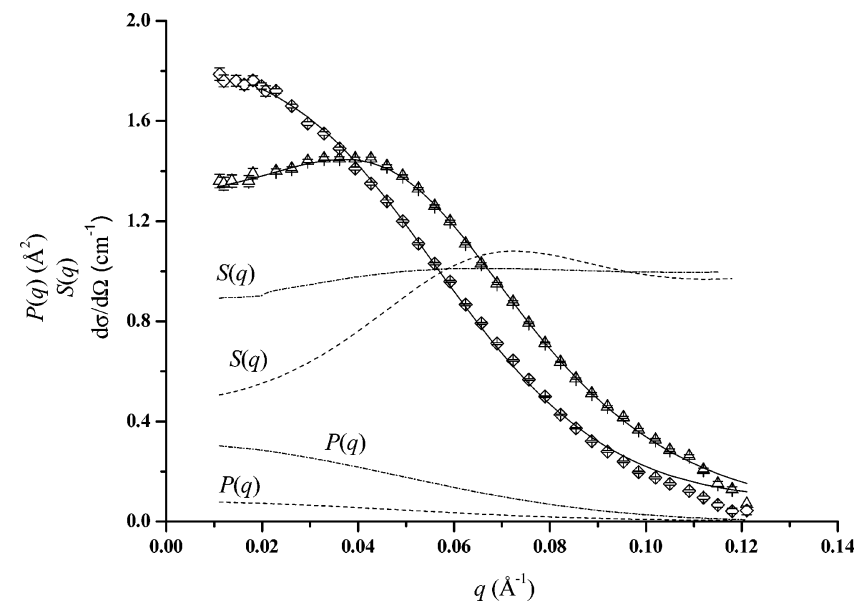

Figure 5. Value for the systems C18DTPAGlu (0.0190 mol kg-1)$\mathrm{D}_{2} \mathrm{O}$ and C18DTPAGlu(Gd) $\left(0.00794 \mathrm{~mol} \mathrm{~kg}{ }^{-1}\right)-\mathrm{D}_{2} \mathrm{O}$ analyzed according to the model described in the text. System C18DTPAGlu $\left(0.0190 \mathrm{~mol} \mathrm{~kg}^{-1}\right)-\mathrm{D}_{2} \mathrm{O}$ : (- - -) structure and form factor, $(\triangle)$ scattering cross section. System C18DTPAGlu(Gd) $\left(0.00794 \mathrm{~mol} \mathrm{~kg}^{-1}\right)-\mathrm{D}_{2} \mathrm{O}$ : $(-\bullet-)$ structure and form factor, $(\diamond)$ scattering cross section.

C18DTPAGlu with its gadolinium complex C18DTPAGlu(Gd) results in a strong increase of scattering cross section if compared with the system C18DTPAGlu $-\mathrm{D}_{2} \mathrm{O}$ at the same concentration.

To gain quantitative data, we have performed nonlinear leastsquares fitting of eq 1 on the experimental cross sections extracting $N_{\text {agg }}, z$, and $n_{\mathrm{w}}$ as unknown parameters. Due to the low concentrations analyzed, we have replaced where needed the molar concentration with the molality.

Figure 4 shows the fitting lines obtained that match quite well the experimental data, while Table 1 collects the obtained results. In Figure 5 the calculated form and structure factors for C18DTPAGlu- $\mathrm{D}_{2} \mathrm{O}\left(0.0192 \mathrm{~mol} \mathrm{~kg}^{-1}\right)$ and C18DTPAGlu$(\mathrm{Gd})-\mathrm{D}_{2} \mathrm{O}\left(0.00794 \mathrm{~mol} \mathrm{~kg}{ }^{-1}\right)$ are shown. The shape of the curve at low $q$ is dominated in both cases by the $S(q)$, while the form factor dominates at higher $q$. However, inspection of the figure shows a wide variation in the structure factor value for the system containing micelles with Gd with respect to that of the C18DTPAGlu micelle. This reflects the substantial difference of the surface charge density of the two micelles.

Inspection of experimental data collected in Table 1 allows further considerations. The extracted structural micelle parameters obtained from the fitting of eq 1 to the SANS data of C18DTPAGlu at different concentrations suggest no significant change in the micelle shape. It is worth noting that for the system at high concentration the micelles were also modeled as ellipsoid aggregates. However a better fit was always obtained when the spherical two-shell model was used. Thus the aggregates formed by C18DTPAGlu are spherical micelles with a mean aggregation number of $\sim 43$, with a value of the total radius $R_{2}$ of $\sim 36 \AA$. Both values are in discrete agreement with those measured through fluorescence quenching $\left(N_{\text {agg }} \approx 35\right)$ and PGSE-NMR $\left(R_{2} \approx 37 \AA\right)$ techniques and reported elsewhere. ${ }^{16}$ A large number of water molecules are present in the micelle, about 90 molecules per monomer.

Replacement of C18DTPAGlu with its complex C18DTPAGlu$(\mathrm{Gd})$ results in a larger value of the aggregation number $(\sim 65)$ with a consequent growth of micelle radius $\left(R_{2} \approx 40 \AA\right)$, and the actual charge for all the micelles ranges from -26 to -30 , as expected due to the relevant value of the solution ionic strength and Gd presence. ${ }^{25}$

In both cases (in the presence or absence of Gd) a large number of water molecules have been found in the hydrophilic shell. It is presumable that the difference observed in the size of the micelle core, in the two cases, reflects the possible partial penetration of water even in the hydrophobic micelle core. As is well known, amphiphilic molecules liberate the solvophobic contraction when their hydrophobic chains experience a hydrophobic environment, such as that present in the micelle core. ${ }^{26}$ In fact when the C18DTPAGlu molecule is replaced by the complex C18DTPAGlu(Gd), the micelle of the latter seems to be more compact and as a result, a larger size $(\sim 41 \AA)$ and a smaller amount of water $(\sim 78$ molecules) for the surfactant have been measured.

Ternary Systems: C18DTPAGlu-C18L2CCK8- $\mathrm{D}_{2} \mathrm{O}$, C18DTPAGlu(Gd)-C18L2CCK8- $\mathrm{D}_{2} \mathrm{O}$, C18DTPAGluC18L5CCK8- $\mathrm{D}_{2} \mathrm{O}$, and C18DTPAGlu(Gd)-C18L5CCK8$\mathbf{D}_{2} \mathbf{O}$. Addition of C18L2CCK8 or C18L5CCK8 to the C18DTPAGlu $-\mathrm{D}_{2} \mathrm{O}$ or C18DTPAGlu(Gd) $-\mathrm{D}_{2} \mathrm{O}$ systems results in a marked change in the scattering cross section. In particular, as observed in the case of the C18DTPAGlu $-\mathrm{D}_{2} \mathrm{O}$ system, also in the ternaries the scattering profiles exhibit a rising peak whose magnitude and position depend on the concentrations of the species. The magnitude of $\mathrm{d} \sigma / \mathrm{d} \Omega$ at low $q$ values is significantly higher in the ternary systems with respect to that observed for the corresponding system where only C18DTPAGlu or C18DTPAGlu(Gd) is present, as reported in Figures 6 and 7. Since C18L2CCK8 or C18L5CCK8 binary aqueous solutions show a flat scattering cross section, the above

TABLE 1: Fitting Parameters Obtained from C18DTPAGlu $-D_{2} O$ and C18DTPAGlu(Gd) $-D_{2} O$ Solutions

\begin{tabular}{lccccc}
\hline \multicolumn{1}{c}{ system } & $N_{\text {agg }} \pm 3$ & $z \pm 5$ & $n_{\mathrm{w}} \pm 8$ & $R_{1}(\AA) \pm 0.6$ & $d(\AA) \pm 0.7$ \\
\hline C18DTPAGlu $\left(0.00301 \mathrm{~mol} \mathrm{~kg}^{-1}\right)-\mathrm{D}_{2} \mathrm{O}$ & 43 & -30 & 94 & 17.0 & 17.8 \\
C18DTPAGlu $\left(0.0105 \mathrm{~mol} \mathrm{~kg}^{-1}\right)-\mathrm{D}_{2} \mathrm{O}$ & 44 & -32 & 92 & 17.0 & 17.5 \\
C18DTPAGlu $\left(0.0192 \mathrm{~mol} \mathrm{~kg} \mathrm{~kg}^{-1}\right)-\mathrm{D}_{2} \mathrm{O}$ & 41 & -25 & 91 & 20.0 & 20.9 \\
C18DTPAGlu(Gd) $\left(0.0301 \mathrm{~mol} \mathrm{~kg}^{-1}\right)-\mathrm{D}_{2} \mathrm{O}$ & 63 & -24 & 80 & 20.1 & 20.9
\end{tabular}


TABLE 2: Fitting Parameters Obtained from C18DTPAGlu-C18L2CCK8- $\mathrm{D}_{2} \mathrm{O}$ and C18DTPAGlu(Gd) $-\mathrm{C18L2CCK8}-\mathrm{D}_{2} \mathrm{O}$ Solutions

\begin{tabular}{|c|c|c|c|c|c|c|}
\hline system & $N_{\text {agg }} \pm 3$ & $z \pm 7$ & $n_{\mathrm{w}} \pm 5$ & $R_{1}(\AA) \pm 0.7$ & $d(\AA) \pm 0.8$ & $f$ \\
\hline C18DTPAGlu (0.00997 $\left.\mathrm{mol} \mathrm{kg}^{-1}\right)-$ & 41 & -20 & 96 & 17.0 & 17.5 & 0.939 \\
\hline $\begin{array}{l}\text { C18L2CCK8 }\left(0.000651 \mathrm{~mol} \mathrm{~kg}^{-1}\right)-\mathrm{D}_{2} \mathrm{O} \\
\text { C18DTPAGlu }\left(0.0102 \mathrm{~mol} \mathrm{~kg}^{-1}\right)- \\
\text { C18L2CCK8 }\left(0.000871 \mathrm{~mol} \mathrm{~kg}^{-1}\right)-\mathrm{D}_{2} \mathrm{O}\end{array}$ & 43 & -22 & 89 & 17.0 & 17.5 & 0.924 \\
\hline $\begin{array}{l}\text { C18L2CCK8 }\left(0.000871 \mathrm{~mol} \mathrm{~kg}^{-1}\right)-\mathrm{D}_{2} \mathrm{O} \\
\text { C18DTPAGlu }\left(0.0105 \mathrm{~mol} \mathrm{~kg}^{-1}\right)- \\
\text { C18L2CCK8 }\left(0.00163 \mathrm{~mol} \mathrm{~kg}^{-1}\right)-\mathrm{D}_{2} \mathrm{O}\end{array}$ & 44 & -28 & 91 & 17.1 & 17.8 & 0.868 \\
\hline $\begin{array}{l}\text { C18DTPAGlu }\left(0.0204 \mathrm{~mol} \mathrm{~kg}^{-1}\right)- \\
\text { C18L2CCK8 }\left(0.00165 \mathrm{~mol} \mathrm{~kg}^{-1}\right)-\mathrm{D}_{2} \mathrm{O}\end{array}$ & 44 & -24 & 96 & 17.1 & 18.1 & 0.927 \\
\hline $\begin{array}{l}\text { C18DTPAGlu(Gd) }\left(0.0101 \mathrm{~mol} \mathrm{~kg}^{-1}\right)- \\
\text { C18L2CCK8 }\left(0.000910 \mathrm{~mol} \mathrm{~kg}^{-1}\right)-\mathrm{D}_{2} \mathrm{O}\end{array}$ & 65 & -20 & 81 & 19.8 & 20.6 & 0.940 \\
\hline
\end{tabular}

observation confirms that, at least at the imposed concentration, in the ternary system mixed micelles are formed.

As observed for the C18DTPAGlu- $\mathrm{D}_{2} \mathrm{O}$ systems, also for the ternary ones the scattering profile is sensitive to the presence

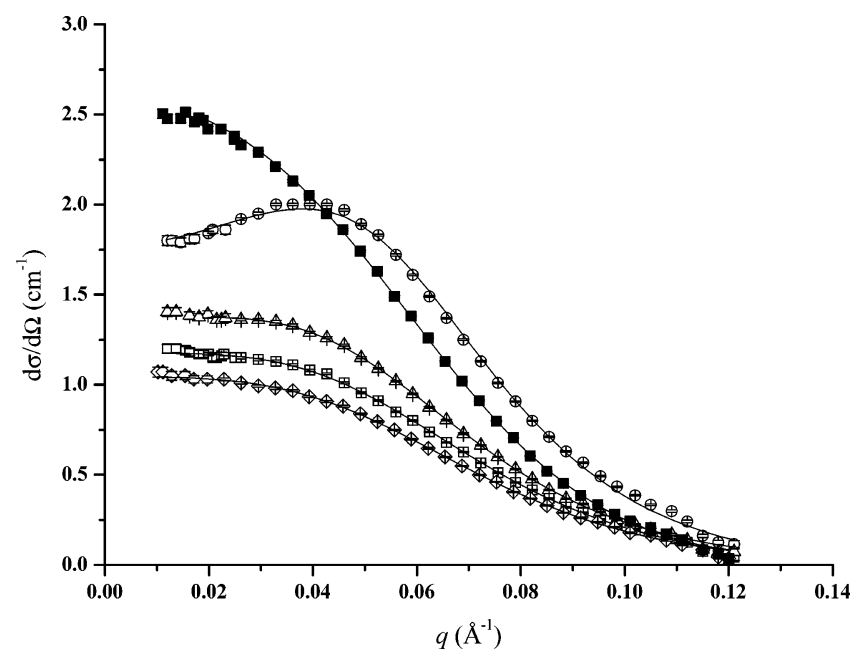

Figure 6. Scattering cross section measured on the following systems: $(\diamond)$ C18DTPAGlu $\left(0.00997 \mathrm{~mol} \mathrm{~kg}^{-1}\right)-$ C18L2CCK8 $\left(0.000651 \mathrm{~mol} \mathrm{~kg}^{-1}\right)-\mathrm{D}_{2} \mathrm{O}$, (口) C18DTPAGlu $\left(0.0102 \mathrm{~mol} \mathrm{~kg}^{-1}\right)-$ C18L2CCK8 $\left(0.000871 \mathrm{~mol} \mathrm{~kg}^{-1}\right)-\mathrm{D}_{2} \mathrm{O},(\triangle)$ C18DTPAGlu $(0.0105$ mol kg $\left.{ }^{-1}\right)-\mathrm{C} 18 \mathrm{~L} 2 \mathrm{CCK} 8\left(0.00163 \mathrm{~mol} \mathrm{~kg}^{-1}\right)-\mathrm{D}_{2} \mathrm{O}$, (O) C18DTPAGlu

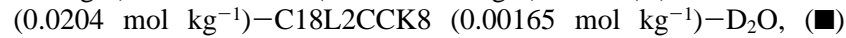
C18DTPAGlu(Gd) $\left(0.0101 \mathrm{~mol} \mathrm{~kg}^{-1}\right)-$ C18L2CCK8 (0.000910 mol $\left.\mathrm{kg}^{-1}\right)-\mathrm{D}_{2} \mathrm{O}$. Solid lines are the fitting curves; see text.

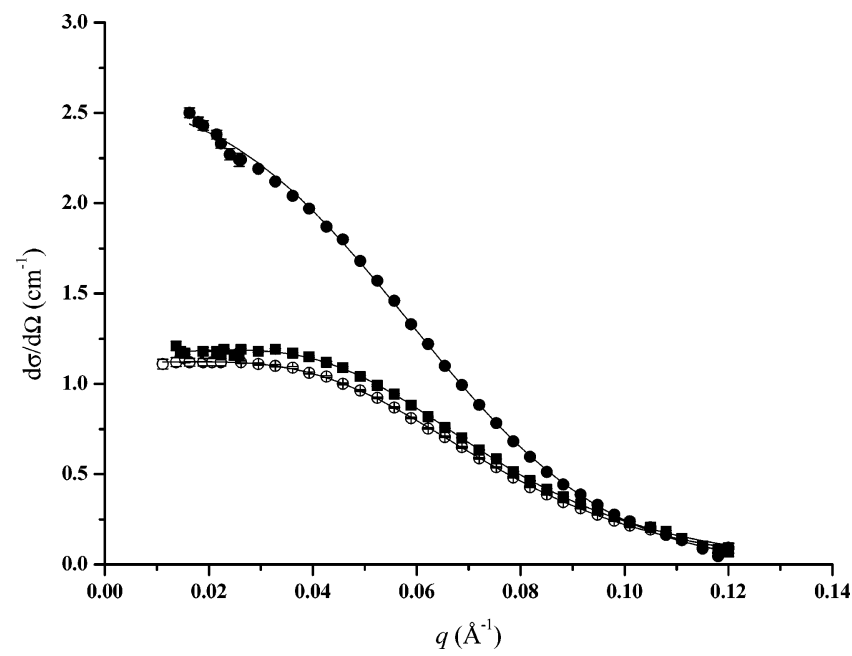

Figure 7. Scattering cross section measured on the following systems: (O) C18DTPAGlu (0.0110 mol kg-1)-C18L5CCK8 (0.000831 mol kg-1)- $\mathrm{D}_{2} \mathrm{O}$, (口) C18DTPAGlu (0.00993 mol kg-1)-C18L5CCK8 $\left(0.00162 \mathrm{~mol} \mathrm{~kg}^{-1}\right)-\mathrm{D}_{2} \mathrm{O},(\bullet)$ C18DTPAGlu(Gd) $\left(0.0101 \mathrm{~mol} \mathrm{~kg}^{-1}\right)-$ C18L5CCK8 $\left(0.00089 \mathrm{~mol} \mathrm{~kg}^{-1}\right)-\mathrm{D}_{2} \mathrm{O}$. Solid lines are the fitting curves, see text. of Gd, while the curve shape seems to be apparently insensitive to the length of the spacer of the molecules containing CCK8 peptide.

Quantitative structural parameters of the aggregates in all ternary systems under investigation have been obtained by a nonlinear least-squares fitting by using the procedure described above. Of course in the present case the micelle composition (evaluated from the $f$ parameters) has been taken into account by using the equation

$$
f=\frac{c_{1}-\left(c_{\mathrm{M}}\right)_{1}}{\mathrm{c}_{1}-\left(c_{\mathrm{M}}\right)_{1}+c_{2}}
$$

where $c_{1}$ and $c_{2}$ represent the analytical concentrations of C18DTPAGlu (or C18DTPAGlu(Gd)) and C18L2CCK8 (or C18L5CCK8), respectively, whereas $\left(c_{\mathrm{M}}\right)_{1}$ is the critical micelle concentration of C18DTPAGlu (or C18DTPAGlu(Gd)). In eq 11 we implicitly suppose that all molecules of C18L $x$ CCK8 participate in mixed micelle formation.

Data extracted from the fitting are collected in Tables 2 and 3.

In general, the structural parameters of the mixed micelles (C18DTPAGlu/C18L $x$ CCK8 or C18DTPAGlu(Gd)/C18L $x$ CCK8) are substantially similar to those obtained for the C18DTPAGluwater and C18DTPAGlu(Gd)-water pure micelles, though some differences have been found in the case of C18L5CCK8.

As observed in the case of the pure C18DTPAGlu micelles also in the mixed aggregates, the presence of $\mathrm{Gd}$ produces a marked increase of the aggregation number, and in turn an increase of their size. Thus as discussed above, the mixed aggregates containing Gd are substantially more compact with respect to those formed by C18DTPAGlu in uncomplexed form.

As mentioned, both mixed aggregates seem to be unaffected by the ratio between the two molecules in the micelle. In fact in most cases the average radius is around $35 \AA$, although for the mixed micelle with the highest content of C18L5CCK8 this values has been found to be slightly larger, $\sim 37 \AA$.

This probably reflects the larger length of C18L5CCK8, which in turn produces an increase of the average micelle size. In this particular case a reasonable good fit of the SANS data has also been obtained with an ellipsoid model, suggesting the tendency of the micelle to elongate as the C18L5CCK8 concentration is raised; see Table 3 .

Finally analysis of the hydrophilic thickness (given by $R_{2}-$ $R_{1}$ ) and the length of the oxoethylene spacers also suggests that the bioactive CCK8 peptide is not completely exposed on the external surface of the micelle in systems containing C18L2CCK8: the length of the two oxoethylene linkers and the glycine residue, present in the shell, did not allow a complete exposition of the bioactive peptide CCK8. In this case the length of the oxoethylene linkers and glycine residue could be too short to allow an efficient exposure of the bioactive peptide beyond the micelle surface. Indeed crystallographic data collected on 
TABLE 3: Fitting Parameters Obtained from C18DTPAGlu-C18CCK8L5- $\mathrm{D}_{2} \mathrm{O}$ and C18DTPAGlu(Gd)-C18L5CCK8-D $2 \mathrm{O}$ Solutions

\begin{tabular}{|c|c|c|c|c|c|c|c|}
\hline system & & $N_{\text {agg }} \pm 3$ & $z \pm 4$ & $n_{\mathrm{w}} \pm 5$ & $R_{1}(\AA) 0.6$ & $d(\AA) \pm 0.5$ & $f$ \\
\hline $\begin{array}{l}\text { C18DTPAGlu }\left(0.0110 \mathrm{~mol} \mathrm{~kg}^{-1}\right)- \\
\text { C18L5CCK8 }\left(0.000831 \mathrm{~mol} \mathrm{~kg}^{-1}\right)-\mathrm{D}_{2} \mathrm{O}\end{array}$ & & 40 & -25 & 88 & 16.6 & 18.8 & 0.924 \\
\hline $\begin{array}{l}\text { C18DTPAGlu }\left(0.00993 \mathrm{~mol} \mathrm{~kg}^{-1}\right)- \\
\text { C18L5CCK8 }\left(0.00162 \mathrm{~mol} \mathrm{~kg}^{-1}\right)-\mathrm{D}_{2} \mathrm{O}\end{array}$ & sphere & 36 & -28 & 96 & 16.0 & 20.6 & 0.863 \\
\hline $\begin{array}{l}\text { C18DTPAGlu }\left(0.00993 \mathrm{~mol} \mathrm{~kg}^{-1}\right)- \\
\text { C18L5CCK8 }\left(0.00162 \mathrm{~mol} \mathrm{~kg}^{-1}\right)-\mathrm{D}_{2} \mathrm{O}\end{array}$ & ellipsoid & 38 & -30 & 80 & $\begin{array}{l}\text { minor axis } \\
16 \\
\text { major axis } \\
18\end{array}$ & $\begin{array}{l}\text { thickness } \\
18\end{array}$ & 0.863 \\
\hline $\begin{array}{l}\text { C18DTPAGlu(Gd) }\left(0.0101 \mathrm{~mol} \mathrm{~kg}^{-1}\right)- \\
\text { C18L5CCK8 }\left(0.00089 \mathrm{~mol} \mathrm{~kg}{ }^{-1}\right)-\mathrm{D}_{2} \mathrm{O}\end{array}$ & & 63 & -20 & 80 & 19.3 & 21.7 & 0.941 \\
\hline
\end{tabular}

PEG give for a chain of two oxoethylenes a value of $\sim 12 \AA$. Thus probably a considerable part of the bioactive peptide of C18L2CCK8 could be hidden among the DTPA moieties. This could reduce the specificity of a mixed micelle in binding the overexpressed proteins of tumor cells.

In contrast, in the mixed aggregates containing C18L5CCK8 there should be a complete exposition of the CCK8 peptide externally to the micelles. In fact in this case the length of the spacer, according to the crystallographic data, should be around $30 \AA$, i.e., quite larger of the length of the shell thickness.

\section{Concluding Remarks}

The structural parameters of pure and mixed microstructure of new amphiphilic molecules have been obtained by small angle neutron scattering measurements. The two surfactants are formed by the same hydrophobic tail, 18 carbon atoms, and two different headgroups: DTPAGlu chelating agent, able to coordinate gadolinium ion, and CCK8, C-terminal cholecystokinin octapeptide amide that shows high affinity for cholecystokinin receptors. These new amphiphilic molecules form mixed aggregates that due to their high specificity and efficiency could be potential new contrast agents in the MRI technique. Due to this, the molecule derivatized with DTPAGlu has been used in complexed and uncomplexed form with Gd(III), while in the case of the molecule containing CCK8, to ensure an efficient exposure of the peptide on the micelle surface, two different spacers of different length were considered. The overall picture of the SANS data collected on systems where the selfaggregation takes place is consistent with spherical micelles.

In particular C18DTPAGlu in complexed or uncomplexed form with $\mathrm{Gd}$ exhibits a cooperative aggregation, whereas no presence of aggregates has been detected for C18L2CCK8 and C18L5CCK8 up to their solubility limit.

For either pure C18DTPAGlu or C18DTPAGlu(Gd) no obvious micelle size growth was noticed in the concentration range studied. However the aggregation number of the C18DTPAGlu(Gd) micelles, as well as their size, has been found to be substantially higher than that measured for the corresponding C18DTPAGlu. This probably reflects the reduction of the charge borne by the DTPAGlu moiety due to the presence of $\mathrm{Gd}^{3+}$. Yet the number of water molecules for surfactant present in the micelle is quite less when the aggregate is formed by C18GluDTPA(Gd). This suggests a more compact packing of the surfactant containing Gd.

In the case of ternary systems the SANS data suggest mixed micelle formation.

From the structural point of view the mixed micelles are essentially similar to the corresponding pure C18DTPAGlu aggregates. This is probably due to both the large size of the C18DTPAGlu hydrophilic head and its considerable amount in the micelle. Finally the collected results suggest that, as expected, using C18L5CCK8 a more efficient exposure of CCK8 on the mixed micelle surface is obtained.
Acknowledgment. We are grateful to Bracco Imaging SpA, Milan (Italy), for funding and for providing the DTPAGlu compound. We also want to thank Dr. Eliana Gianolio for preparing the gadolinium complexes used in our experiments. Some of us (G.M., L.P., F.L.C.) wish to thank the Institut für Festkörperforschung for provision of beam time.

\section{References and Notes}

(1) Weissleder, R.; Mahmood, U. Radiology (Oak Brook, Ill) 2001, 219, 316-333.

(2) Aime, S.; Cabella, C.; Colombatto, S.; Geninatti Crich, S.; Gianolio, E.; Maggioni, F. J. Magn. Reson. Imaging 2002, 16, 394-406.

(3) Glogard, C.; Stensrud, G.; Hovland, R.; Fossheim, S. L.; Klaveness, J. Int. J. Pharm. 2002, 233, 131-140.

(4) Morel, S.; Terreno, E.; Ugazio, E.; Aime, S.; Gasco, M. R. Eur. J. Pharm. Biopharm. 1998, 45, 157-163.

(5) Anelli, P. L.; Lattuada, L.; Lorusso, V.; Schneider, M.; Tournier, H.; Uggeri, F. Magn. Reson. Mater. Phys., Biol. Med. 2001, 12, 114-120.

(6) Wiener, E. C.; Brechbiel, M. W.; Brothers, H.; Magin, R. L.; Gansow, O. A.; Tomalia, D. A.; Lauterbur, P. C. Magn. Reson. Med. 1994, $31,1-8$.

(7) Aime, S.; Botta, M.; Garino, E.; Geninatti Crich, S.; Giovenzana, G.; Pagliarin, R.; Palmisano, G.; Sisti, M. Chem.-Eur. J. 2000, 6, 26092617.

(8) Bligh, S. W.; Harding, C. T.; Sadler, P. J.; Bulman, R. A.; Bydder, G. M.; Pennock, J. M.; Kelly, J. D.; Latham, I. A.; Marriott, J. A. Magn. Reson. Med. 1991, 17, 516-532.

(9) Schmiedl, U.; Ogan, M.; Paajanen, H.; Marotti, M.; Crooks, L. E.; Brito, A. C.; Brasch, R. C. Radiology (Oak Brook, Ill) 1987, 162, 205210.

(10) Liu, S.; Edwards, D. S. Chem. Rev. (Washington, D.C.) 1999, 9, $2235-2268$

(11) Torchilin, V. P. Adv. Drug Delivery Rev. 2002, 54, 235-252.

(12) Andre, J. P.; Toth, E.; Fischer, H.; Seelig, A.; Macke, H. R.; Merbach, A. E. High relaxivity for monomeric Gd(DOTA)-based MRI contrast agents, thanks to micellar self-organization. 1999, 5, 2977-2983.

(13) Reubi, J. C.; Schaer, J. C.; Waser, B. Cancer Res. 1997, 57, 13771386

(14) Silvente-Poirot, S.; Dufresne, M.; Vaysse, N.; Fourmy, D. Eur. J. Biochem. 1993, 215, 513-529.

(15) Wank, S. A. Am. J. Phys. 1995, 269, G628-G646.

(16) Accardo, A.; Tesauro, D.; Roscigno, P.; Gianolio, E.; Paduano, L.; D'Errico, G.; Pedone, C.; Morelli, G. J. Am. Chem. Soc. 2004, 126, 30973107.

(17) Anelli, P. L.; Fedeli, F.; Gazzotti, O.; Lattuada, L.; Lux, G.; Rebasti, F. Bioconj. Chem. 1999, 10, 137-140.

(18) White, P. D.; Chan, W. C. Basic Procedures in Fmoc Solid-Phase Peptide Synthesis; Oxford University Press Inc.: New York, 2000.

(19) Wignall, G. D.; Bates, F. S. J. Appl. Crystallogr. 1987, 20, $28-$ 40.

(20) Russell, T. P.; Lin, J. S.; Spooner, S.; Wignall, G. D. J. Appl. Crystallogr. 1988, 21, 629-638.

(21) Kotlarchyk, M.; Chen, S. H. J. Chem. Phys. 1983, 79, 2461-2469.

(22) Hayter, J. B.; Penfold, J. J. Chem. Soc., Faraday Trans. 1 1981, $77,1851-1863$

(23) Hayter, J. B.; Penfold, J. Mol. Phys. 1981, 42, 109-118.

(24) Tanford, C. J. Phys. Chem. 1972, 76, 3020-3024.

(25) Evans, D. F.; Wennerstrom, H. The Colloidal Domain: Where Physics, Chemistry, Biology and Technology Meet; Wiley-VCH: New York, 1999.

(26) Hannak, R. B.; Färber, G.; Konrat, R.; Kraeutler, B. J. Am. Chem. Soc. 1997, 119, 2313-2314. 